\title{
BMJ Open Infant feeding and risk of developing celiac disease: a systematic review
}

\author{
Marco Silano, ${ }^{1}$ Carlo Agostoni, ${ }^{2}$ Yolanda Sanz, ${ }^{3}$ Stefano Guandalini ${ }^{4}$
}

To cite: Silano $M$,

Agostoni C, Sanz Y, et al. Infant feeding and risk of developing celiac disease: a systematic review. BMJ Open 2016;6:e009163.

doi:10.1136/bmjopen-2015009163

- Prepublication history for this paper is available online. To view these files please visit the journal online (http://dx.doi.org/10.1136/ bmjopen-2015-009163).

Received 22 June 2015 Revised 21 September 2015 Accepted 6 October 2015

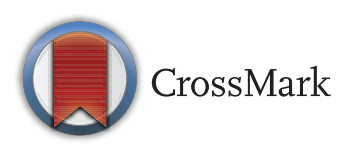

${ }^{1}$ Unit of Human Nutrition and Health, Istituto Superiore di Sanità, Roma, Italy

${ }^{2}$ Pediatric Clinic, Department of Clinical Sciences and Community Health, University of Milan, Fondazione IRCCS

Cà Granda, Ospedale

Maggiore Policlinico, Milan, Italy

${ }^{3}$ Department of Microbial Ecology, Nutrition \& Health Research Group, Institute of Agrochemistry and Food Technology, National Research Council (IATACSIC), Valencia, Spain ${ }^{4}$ Section of Pediatric Gastroenterology, Hepatology and Nutrition, Department of Pediatrics, University of Chicago, Chicago, Illinois, USA

Correspondence to Dr Marco Silano; marco.silano@iss.it

\section{ABSTRACT}

Objective: To review the evidence for the association of breast feeding, breastfeeding duration or the timing of gluten introduction and the later development of celiac disease (CD).

Design: Systematic review.

Methods: We searched MEDLINE, via PubMed, EMBASE and Web of Science, for studies published up to 31 August 2015 investigating the association of breastfeeding duration, breast feeding at the moment of gluten introduction or the timing of gluten introduction and the later development of $\mathrm{CD}$. Prospective studies had to enrol infants/children at high risk of $C D$. For retrospective studies, participants had to be children or adults with $C D$. The paper quality was assessed by means of a GRADE score and the bias risk was assessed by the Newcastle-Ottawa Scale (for observational cohort studies) and Cochrane Collaboration's tool (for randomised trials).

Results: Out of 149 retrieved papers, 48 were considered in depth and 16 were included in this review (9 were prospective and 2 were interventional). We found that neither duration of breastfeeding nor breastfeeding at time of gluten introduction nor the delayed introduction of gluten during weaning were effective in preventing later development of $C D$.

Conclusions: Currently, there is no evidence on the optimal breastfeeding duration or the effects of avoiding early ( $<4$ months of age) or late ( $\geq 6$ or even at 12 months) gluten introduction in children at risk of CD. Accordingly, no specific general recommendations about gluten introduction or optimal breastfeeding duration can be presently provided on evidence-based criteria in order to prevent $\mathrm{CD}$.

\section{INTRODUCTION}

Celiac disease $(\mathrm{CD})$ is a permanent immunemediated enteropathy, triggered in genetically predisposed individuals by gluten. Gluten is a protein fraction of cereals, such as wheat, rye and barley. The genetic predisposition consists in the presence of alleles encoding for the molecules DQ2 or DQ8 of the human leucocyte antigen (HLA). ${ }^{1-3}$

$\mathrm{CD}$ is probably the best known multifactorial disease. Genetic predisposition and gluten intake are both necessary, but not sufficient for the development of this condition. Only roughly $5 \%$ of the DQ2/8+ worldwide

\section{Strengths and limitations of this study}

- Our systematic review offers an inclusive overview of the population-based evidence regarding infant feeding practices and the risk of developing celiac disease (CD).

- A study quality score and a bias risk scale are used to appraise the clinical transferability of each study included in this systematic review.

- A small number of prospective clinical trials are available about the role of breast feeding and the gluten introduction during weaning. The majority of the studies were retrospective and enrolled children not at genetic risk for $C D$.

- No specific general recommendations about gluten introduction or optimal breastfeeding duration can be presently provided on evidencebased criteria in order to prevent CD. A possible exception might be DQ2 homozygous girls, in whom an early introduction of gluten appears to be associated with a greater risk of subsequent development of $C D$.

population will eventually develop $\mathrm{CD} .{ }^{4}$ Therefore, other factors are expected to be involved in CD pathogenesis. Among these, additional genes are increasingly being recognised; but repeated viral infections, modality of delivery, imbalance of the intestinal microbiota and infant feeding practices have also been hypothesised. ${ }^{5-8}$

The hypothesis of inducing, via early feeding practices, oral tolerance to gluten in infants at genetic risk for $\mathrm{CD}$, has been long investigated. Both prolonged breast feeding and gluten introduction during a sensitive 'window' period, in which the infant's immune system is more likely to adapt to food antigens, have been assumed as protective factors towards the development of $\mathrm{CD} .{ }^{8}$

The epidemiological evidence about this strategy for the primary prevention of $\mathrm{CD}$ is conflicting and definitive recommendations on early feeding in children at genetic risk for $\mathrm{CD}$ are not available.

The aim of this paper is, therefore, to systematically review all the related published clinical trials and cohort studies, in order to 
assess whether: (1) breastfeeding practice and breastfeeding duration protects from the development of $\mathrm{CD}$; (2) breast feeding at time of gluten introduction exerts a protective effect on CD risk; (3) timing of gluten introduction may have a role in triggering $\mathrm{CD}$; (4) the amount of gluten during the complementary feeding period plays a role in the onset of $\mathrm{CD}$. These evidences are then critically discussed to assess the appropriate timing of first gluten introduction during weaning, also in the light of the role of the other environmental variables.

\section{MATERIALS AND METHODS}

\section{Search strategy}

A systematic review of the literature was initially performed in November 2014, and then repeated in December 2014 and on 1 September 2015. The search was carried out in the content of MEDLINE, via PubMed (http://www.ncbi.nlm.nih.gov/pubmed) EMBASE and Web of Science, following guidelines from the Preferred Reporting Items for Systematic Reviews and Meta-Analyses (PRISMA) group. Letters to the editor, abstracts and proceedings from scientific meetings were excluded from the analysis. Only papers in English were considered. Two authors (MS and CA) independently selected the articles, and retrieved and assessed the potentially relevant ones. Discrepancies in article selection were resolved by a face-to-face discussion; if the discrepancy stood, a third researcher was consulted (YS). The following search terms were used: ('celiac' OR 'coeliac' OR 'sprue' OR 'gluten enteropathy') and (breast-feeding OR breastfeeding OR breast feeding OR breastfed); ('celiac' OR 'coeliac' OR 'sprue' OR 'gluten enteropathy') and ('weaning' OR 'complementary feeding'); ('gluten') and ('time OR timing') and ('introduction'); ('gluten') and ('infant feeding') ('celiac' OR 'coeliac' OR 'sprue' OR 'gluten enteropathy') and ('infant feeding').

\section{Inclusion criteria}

Types of study

Any type of study on humans, reporting primary data, was included in this systematic review. Previous systematic reviews and meta-analyses were excluded.

\section{Types of participants}

The prospective studies had to enrol infants/children at increased risk of developing CD. Risk of developing CD was intended as defined by HLA DQ2/8 positivity and/ or at least a first-degree relative with $\mathrm{CD}$ or type 1 diabetes mellitus (T1DM). For retrospective studies, participants had to be children or adults with CD diagnosed by small bowel biopsy or serological positivity (anti-tissue transglutaminase (tTG) antibodies).

To be included in this analysis, the studies should have assessed the risk of $\mathrm{CD}$ in people who were:

- Ever breast fed compared with those never breast fed;
- Breast fed for different periods of time;

- Breast fed at the time of the first gluten introduction during weaning compared with those who were not;

- Receiving gluten for the first time during weaning at different ages.

\section{Outcome measures}

The primary outcome measures were the development of CD-associated autoimmunity (anti-tTG antibodies) and/or biopsy-proven CD.

\section{Data collection, extraction and analysis}

An initial evaluation of the title, abstract and keywords of every record found was performed by MS and CA. The next step was the retrieval of the full text of potentially relevant trials. The two reviewers independently assessed the eligibility of each potentially relevant trial with the use of inclusion criteria. If they had different opinions, these were resolved by discussion with the third reviewer (YS).

The information extracted included the following: (1) general characteristics of the studies (first author and year of publication of the article, country, number and age of the participants, inclusion and exclusion criteria; (2) design and characteristics of the data collection and eventual intervention; (3) definition of the outcome (CD diagnosis, autoimmunity); and (4) main results. Main summary measure was considered HR/OR.

\section{Study quality}

In order to appraise the quality of the studies included in this review, we used the GRADE score ranging from 0 (minimum) to 4 (maximum) points. GRADE is a systematic and explicit approach to making judgements about quality of evidence, based on a score given to each study according to the following parameters: study design (prospective or observational), allocation process, follow-up, withdrawals, directness consistency and effect size. ${ }^{9}$

\section{ASSESSIMENT OF RISK OF BIAS}

For observational cohort studies, we used the Newcastle-Ottawa Scale to assess the risk of bias. ${ }^{10}$ This scale uses a star system (with a maximum of nine stars) to evaluate a study in three domains: selection of participants, comparability of study groups and the ascertainment of outcomes of interest. We judged studies that received a score of nine stars to be at low risk of bias, studies that scored seven or eight stars to be at medium risk and those that scored six or less to be at high risk of bias. Similarly, for the randomised trials, we used the Cochrane Collaboration's tool for assessing the risk of bias. ${ }^{11}$ This tool evaluates seven possible sources of bias: random sequence generation, allocation concealment, blinding of participants and personnel, blinding of outcome assessment, incomplete outcome data, selective reporting and other bias. For each individual domain, 
we classified studies into low, unclear and high risk of bias.

\section{RESULTS}

\section{Studies included in the review}

Our systematic search through MEDLINE, EMBASE and Web of Science retrieved 149 papers. Of them, 48 papers were potentially considered eligible for inclusion. We obtained the full text of those papers and, after the exclusion of 20 review articles, a commentary and a letter, 11 original research articles were also excluded because they did not meet the inclusion criteria. In detail, the reasons for exclusion were as follows: absence of data about breastfeeding duration and/or the age of gluten introduction, no CD diagnosis or CD autoimmunity as outcome of the study and lack of negative/ healthy controls. Thus, 16 papers reporting the results of 16 different studies were included in the analysis.

Of the 16 studies included in this review, nine were prospective (two interventional and seven observational). The interventions consisted of the prescription of gluten introduction (no indication about the amount) at 6 or 12 months of age in the CeliPrev Study $^{12}$ and the daily administration of $100 \mathrm{mg}$ of gluten at 16-24 weeks of age in the PreventCD study, ${ }^{13}$ respectively.

Three studies were based on populations of children at genetic risk of T1DM. ${ }^{14-16}$ Three studies had a multicentric study design. ${ }^{12} 1316$ Most papers (13) were from Europe, with 3 from Italy, ${ }^{12} 17184$ from Sweden, ${ }^{19-22} 3$ from Germany ${ }^{14}{ }^{23-24}$ and 1 each from the $\mathrm{UK},{ }^{25}$ Norway $^{26}$ and the Netherlands; ${ }^{27} 1$ was multicentric with groups from Europe and the USA, ${ }^{16}$ and 1 was a European study funded by the seventh European research framework programme. ${ }^{13}$ The remaining study was from the USA. ${ }^{15}$

\section{Breast feeding and risk of CD}

Ten of the 16 papers investigating the effect of breast feeding on the risk of CD concluded that the duration of breast feeding did not show a preventive effect on the development of CD. These studies included the most recent and consequently those with the highest quality score, represented by the two randomised interventional $^{12}{ }^{13}$ as well as eight of the nine prospective studies considered in the analysis. ${ }^{14-16}{ }^{22-27}$ One of these studies even found a positive correlation between prolonged breast feeding for over the first year of age and the increased incidence of $\mathrm{CD}$, although the statistical significance of this association was only minimal. ${ }^{26}$ A protective effect of breast feeding on the later development of $\mathrm{CD}$ was reported by four retrospective papers (table 1). ${ }^{17-19} 23$

\section{Breast feeding at gluten introduction and CD}

Nine of the 16 studies included in this review examined the effect of breast feeding at the time of gluten introduction on later development of CD (table 2). Among these, two retrospective studies, enrolling individuals whose genetic background was not studied, as controls, found a preventive effect of being breast fed at the first ingestion of gluten during the introduction of solid foods, with a relevant statistical significance (OR ranging from 0.35 to 0.55$){ }^{19} 23$

However, none of the six prospective papers did not report such a protective effect. ${ }^{12} 1315162126$ This group of studies includes the most recent study as well as those with the highest quality score, characteristically including children with a common genetic background (predisposing to a risk for $\mathrm{CD}$ or T1DM or DQ2/8+ positive children).

\section{Time of gluten introduction and CD}

Eight of the 11 papers reporting information about the time of gluten introduction did not find any correlation between the age of the children at this stage and development of CD (table 3). The recent paper by Lionetti et $a l^{12}$ concluded that there is no difference in CD incidence at 5 years of age in children who have gluten introduced at 6 months compared with those who have consumed gluten for the first time at 12 months (HR $0.9 ; 95 \%$ CI 0.6 to 1.4 ). Also, no difference in the incidence of $\mathrm{CD}$ between the two groups, by stratifying the children for the genetic risk (homozygosis or heterozygosis for the DQ2), resulted in this study.

These results were similar to those simultaneously reported by a recent survey that found a similar CD incidence at 3 years of age in children who received a daily dose of $100 \mathrm{mg}$ of gluten between 16 and 24 weeks of age and the children who began receiving gluten at 24 weeks $(1.23$; $95 \%$ CI 0.79 to 1.91$) .{ }^{13}$ Likewise, the $\mathrm{R}$ generation study concluded that there was no difference in the development of $\mathrm{CD}$ autoimmunity whether gluten is introduced before or after 6 months of age. ${ }^{27}$

The results of both these studies are in agreement with the conclusions of the most recent paper, which reports the results of the multicentric TEDDY study. According to this study, neither the early ( $<17$ weeks) nor the delayed introduction of gluten-containing cereals ( $>26$ weeks) is a risk factor for the later development of CD-associated autoimmunity and biopsy-proven CD. ${ }^{16}$

On the contrary, the Norwegian study reported a slightly increased risk for children introduced to gluten when complementary feeding was started after 6 months of age (OR 1.27; 95\% CI 1.01 to 1.65), but not for those receiving gluten before 4 months of age. ${ }^{26}$ Only one paper described an increased risk of developing CD-related autoimmunity in two groups of children introduced to gluten earlier and later, respectively, than the reference period (4-7 months of age) ${ }^{15}$ However, the significance for the group exposed to gluten after 7 months of age was very narrow, with a HR of 1.87 (95\% CI 0.97 to 3.60), while the fivefold risk shown by children introduced to gluten before 3 months of age 


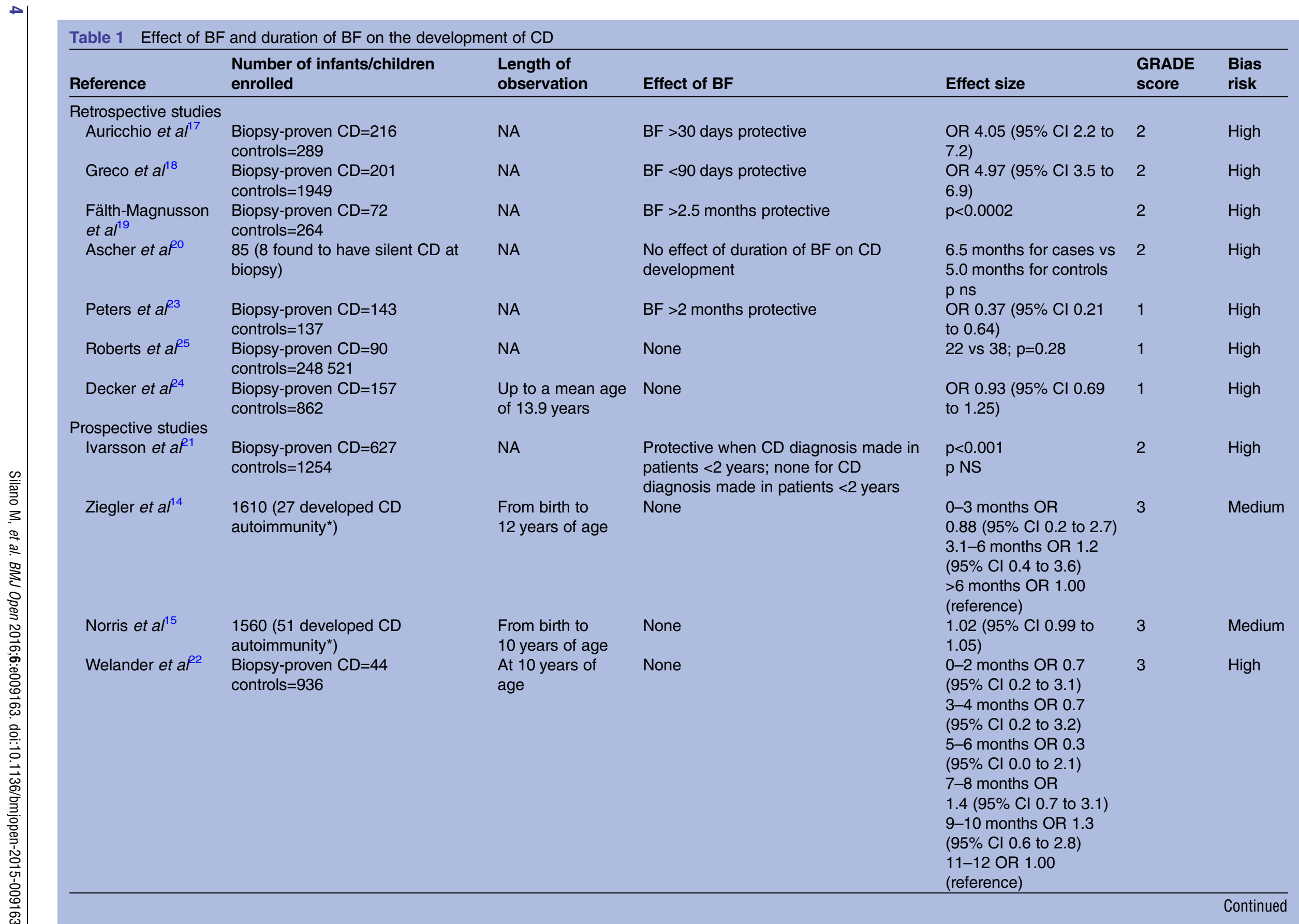

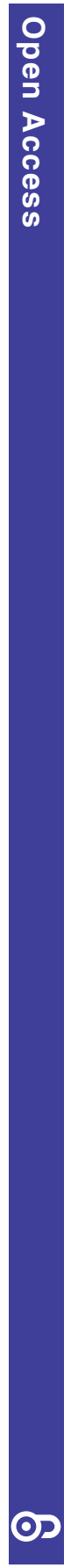

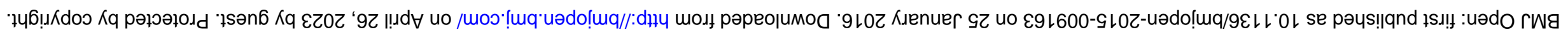




\begin{tabular}{|c|c|c|c|c|c|c|}
\hline Reference & $\begin{array}{l}\text { Number of infants/children } \\
\text { enrolled }\end{array}$ & $\begin{array}{l}\text { Length of } \\
\text { observation }\end{array}$ & Effect of BF & Effect size & $\begin{array}{l}\text { GRADE } \\
\text { score }\end{array}$ & $\begin{array}{l}\text { Bias } \\
\text { risk }\end{array}$ \\
\hline Størdal et $a^{26}$ & $\begin{array}{l}\text { Biopsy-proven } C D=324 \\
\text { controls=81 } 834\end{array}$ & $\begin{array}{l}\text { From birth to } \\
12 \text { years of age }\end{array}$ & $\mathrm{BF}>1$ year predisposing & $\begin{array}{l}<6 \text { months reference } \\
6-12 \text { months OR } 1.27 \\
(95 \% \text { Cl } 0.85 \text { to } 1.86) \\
>13 \text { months OR } 1.49 \\
(95 \% \text { Cl } 1.01 \text { to } 2.21 \text { ) }\end{array}$ & 3 & High \\
\hline Jansen, $2014^{27}$ & $\begin{array}{l}1679 \text { ( } 43 \text { developed CD } \\
\text { autoimmunity }{ }^{\star} \text { ) }\end{array}$ & At 6 years of age & $\begin{array}{l}\text { No difference in proportion of BF } \\
\text { children in group who developed or do } \\
\text { not have autoimmunity }\end{array}$ & $\mathrm{p}$ ns & 3 & Medium \\
\hline Vriezinga et $a l^{13}$ & $\begin{array}{l}944 \text { (105 developed CD } \\
\text { autoimmunity*, out of them } 77 \\
\text { biopsy-proven overt CD) }\end{array}$ & $\begin{array}{l}\text { From birth to } \\
3 \text { years of age }\end{array}$ & None & $\begin{array}{l}\text { Overt CD } \\
0 \text { months OR } 0.90(95 \% \\
\text { Cl } 0.22 \text { to } 3.6) \\
<3 \text { months OR } 1.3(95 \% \\
\text { Cl } 0.41 \text { to } 4.1) \\
4-5 \text { months OR } 1.5 \\
\text { ( } 95 \% \text { Cl } 0.57 \text { to } 4.1) \\
>6 \text { months OR } 1.2(95 \% \\
\text { Cl } 0.67 \text { to } 2.2)\end{array}$ & 4 & Low \\
\hline Lionetti et $a^{12}$ & $\begin{array}{l}832 \text { (117 developed CD } \\
\text { autoimmunity, }{ }^{*} \text { out of them } 86 \\
\text { biopsy-proven overt CD) }\end{array}$ & $\begin{array}{l}\text { From birth to } \\
10 \text { years of age }\end{array}$ & None & $\begin{array}{l}\mathrm{CD} \text { autoimmunity } \\
\mathrm{OR}=1.0(95 \% \mathrm{Cl} 0.9 \text { to } \\
1.0) \\
\text { Overt } \mathrm{CD} \\
\mathrm{OR}=1(95 \% \mathrm{Cl} 0.9 \text { to } \\
1.1)\end{array}$ & 4 & Low \\
\hline
\end{tabular}

*Serological positivity of tTG antibodies.

BF, breast feeding; CD, celiac disease; NA, not available; NS, not significant; tTG, tissue transglutaminase. 
Table 2 Effect of $B F$ at the time of gluten introduction on the development of $C D$

\begin{tabular}{|c|c|c|c|c|c|}
\hline Reference & $\begin{array}{l}\text { Number of infants/children } \\
\text { enrolled }\end{array}$ & $\begin{array}{l}\text { Effect of BF } \\
\text { during gluten } \\
\text { introduction }\end{array}$ & Effect size & $\begin{array}{l}\text { GRADE } \\
\text { score }\end{array}$ & $\begin{array}{l}\text { Bias } \\
\text { risk }\end{array}$ \\
\hline \multicolumn{6}{|l|}{ Retrospective studies } \\
\hline Fälth-Magnusson et al ${ }^{19}$ & $\begin{array}{l}\text { Biopsy-proven } C D=72 \\
\text { controls=264 }\end{array}$ & Protective & $\begin{array}{l}\text { OR } 0.35(95 \% \mathrm{Cl} \\
0.17 \text { to } 0.66)\end{array}$ & 2 & High \\
\hline Ascher et $a{ }^{20}$ & $\begin{array}{l}85 \text { (8 found to have silent CD } \\
\text { at biopsy) }\end{array}$ & None & NS & 2 & High \\
\hline Peters et $a P^{33}$ & $\begin{array}{l}\text { Biopsy-proven } \mathrm{CD}=143 \\
\text { controls }=137\end{array}$ & Protective & $\begin{array}{l}\text { OR } 0.46(95 \% \mathrm{Cl} \\
0.27 \text { to } 0.78)\end{array}$ & 1 & High \\
\hline \multicolumn{6}{|l|}{ Prospective studies } \\
\hline Ivarsson et $a^{21}$ & $\begin{array}{l}\text { Biopsy-proven CD=627 } \\
\text { controls }=1254\end{array}$ & Protective & $\begin{array}{l}\text { OR } 0.55(95 \% \mathrm{Cl} \\
0.4 \text { to } 0.77)\end{array}$ & 2 & High \\
\hline Norris et al ${ }^{15}$ & $\begin{array}{l}1560 \text { (51 developed CD } \\
\text { autoimmunity*) }\end{array}$ & None & $\begin{array}{l}\text { OR }=1.32(95 \% \\
\text { Cl } 0.76 \text { to } 2.28)\end{array}$ & 3 & Medium \\
\hline Størdal et $a{ }^{26}$ & $\begin{array}{l}\text { Biopsy-proven CD=324 } \\
\text { controls }=81834\end{array}$ & None & $\begin{array}{l}\mathrm{BF}>1 \text { months } \\
\text { after introduction } \\
\mathrm{OR} 1.17 \text { ( } 95 \% \mathrm{Cl} \\
0.74 \text { to } 1.87) \\
\mathrm{BF}<1 \text { months } \\
\text { after introduction } \\
\text { OR } 0.65 \text { (95\% Cl } \\
0.37 \text { to } 1.14)\end{array}$ & 3 & High \\
\hline Vriezinga et $a l^{13}$ & $\begin{array}{l}944 \text { (105 developed CD } \\
\text { autoimmunity, }{ }^{*} \text { out of them } 77 \\
\text { biopsy-proven overt CD) }\end{array}$ & None & $\begin{array}{l}\mathrm{OR}=1.35(95 \% \\
\mathrm{Cl} 0.57 \text { to } 4.1)\end{array}$ & 4 & Low \\
\hline Lionetti et al ${ }^{12}$ & $\begin{array}{l}832 \text { (117 developed CD } \\
\text { autoimmunity, }{ }^{*} \text { out of them } 86 \\
\text { biopsy-proven overt CD) }\end{array}$ & One & $\begin{array}{l}\mathrm{CD} \text { autoimmunity } \\
\mathrm{OR}=1.5(95 \% \mathrm{Cl} \\
0.77 \text { to } 3.0) \\
\text { Overt } \mathrm{CD} \\
\mathrm{OR}=1(95 \% \mathrm{Cl} \\
0.6 \text { to } 2.3)\end{array}$ & 4 & Low \\
\hline Aronsson et $a l^{16}$ & $\begin{array}{l}6434 \text { ( } 773 \text { developed } \\
\text { autoimmunity, }{ }^{*} 307 \text { overt } \\
\text { biopsy-proven CD) }\end{array}$ & None & $\begin{array}{l}\text { Overt CD } \\
\text { OR=1.13 }(95 \% \\
\text { Cl } 0.88 \text { to } 1.46)\end{array}$ & 3 & Medium \\
\hline
\end{tabular}

had more robust statistical significance (HR 5.17, 95\% CI 1.44 to 18.57 ).

\section{Amount of gluten at weaning and development of CD}

None of the papers included in our analysis compared the effect of different amount of gluten given to children during weaning on the risk of CD. This aspect is mostly unknown and the scant available data come from a Swedish experience. However, papers reporting the paradigmatic Swedish experience were excluded from the analysis, since negative controls were not included in the description. ${ }^{28}$

\section{DISCUSSION}

\section{Breast feeding and CD}

Our review shows that some studies reported a protective effect of breast feeding on the risk of developing CD while others, on the contrary, reported no effect. The latter are the most recent, and have the highest GRADE score and the lowest bias risk. Accordingly, all the prospective studies included in our analysis, except one, concluded that the duration of breast feeding (exclusive and/or complementary) and/or gluten introduction while the infant is still breast fed had no impact on the risk of developing $\mathrm{CD}$. In addition, the only prospective study to describe a protective effect of breast feeding, reported this effect only in the group of children diagnosed with CD below 2 years of age and not for those diagnosed over this age. These conclusions contrasted with the meta-analysis by Akobeng $e t \quad a l,{ }^{29}$ which reported protection against $\mathrm{CD}$ with longer duration of breast feeding, based on the findings from five earlier retrospective studies (OR $0.48 ; 95 \%$ CI 0.40 to 0.59 ). So, the limited effect of breast feeding found may only represent a delay of the development of the symptoms and clinical signs of $\mathrm{CD}$, rather than being a real prevention of this condition.

This result is quite surprising, since earlier studies and reviews indicated a potential protective effect on $\mathrm{CD}$ 
Table 3 Effect of the time of gluten introduction on the development of $C D$

\begin{tabular}{|c|c|c|c|c|}
\hline Reference & Age of gluten introduction & Effect size & $\begin{array}{l}\text { GRADE } \\
\text { score }\end{array}$ & $\begin{array}{l}\text { Bias } \\
\text { risk }\end{array}$ \\
\hline \multicolumn{5}{|l|}{ Retrospective studies } \\
\hline \multirow[t]{4}{*}{ Fälth-Magnusson et al ${ }^{19}$} & Mean age at gluten & Range 4-7 & 2 & High \\
\hline & introduction: & Range 4-10 & & \\
\hline & 6-month for CD cases & $\mathrm{pNS}$ & & \\
\hline & 6.1 for controls & & & \\
\hline \multirow[t]{6}{*}{ Peters et $a f^{3}$} & Continuous risk per month & HR $0.98(95 \% \mathrm{Cl} 0.86$ to 1.11$)$ & 1 & High \\
\hline & (1-12 months) & HR $0.72(95 \% \mathrm{Cl} 0.29$ to 1.79$)$ & & \\
\hline & $<3$ vs $>3$ months & HR $0.52(95 \% \mathrm{Cl} 0.18$ to 1.44$)$ & & \\
\hline & 3 vs 4 months & HR 1.21 (95\% Cl 0.40 to 3.68$)$ & & \\
\hline & 4 vs 5 months & HR $0.72(95 \% \mathrm{Cl} 0.28$ to 1.85$)$ & & \\
\hline & $>5$ months & & & \\
\hline \multicolumn{5}{|l|}{ Prospective studies } \\
\hline \multirow[t]{3}{*}{ Ivarsson et a ${ }^{1}$} & $1-4$ months & HR $1.4(95 \% \mathrm{Cl} 0.87$ to 2.4$)$ & 2 & High \\
\hline & 5-6 months (reference) & HR 0.76 (95\% $\mathrm{Cl} 0.41$ to 1.4$)$ & & \\
\hline & $7-12$ months & & & \\
\hline \multirow[t]{3}{*}{ Ziegler et al ${ }^{14}$} & $<3$ months & HR 2.3 (95\% Cl 0.3 to 18.2$)$ & 3 & Medium \\
\hline & 3-6 months (reference) & HR $0.7(95 \% \mathrm{Cl} 0.3$ to 1.8$)$ & & \\
\hline & $>6$ months & & & \\
\hline \multirow[t]{3}{*}{ Norris et $a l^{15}$} & $1-3$ months & HR $5.17(95 \%$ Cl 1.44 to & 3 & Medium \\
\hline & 3-4 months (reference) & 18.57) & & \\
\hline & $>7$ months & HR $1.87(95 \% \mathrm{Cl} 0.97$ to 3.60$)$ & & \\
\hline \multirow[t]{3}{*}{ Welander et $a^{P^{2}}$} & $3-4$ months & HR $1.0(95 \% \mathrm{Cl} 0.3$ to 3.3$)$ & 3 & High \\
\hline & 5-6 months (reference) & HR $1.1(95 \% \mathrm{Cl} 0.6$ to 2.0$)$ & & \\
\hline & 7-8 months & & & \\
\hline \multirow[t]{3}{*}{ Størdal et ape } & $<4$ months & OR $1.27(95 \% \mathrm{Cl} 1.01$ to 1.65$)$ & 3 & High \\
\hline & 5-6 months (reference) & OR 1.05 (95\% Cl 0.69 to 1.58$)$ & & \\
\hline & $>6$ months & & & \\
\hline Jansen et $a P^{7}$ & $>6$ months & NS & 3 & Medium \\
\hline Vriezinga et $a l^{13}$ & $16-24$ weeks & HR $1.23(95 \% \mathrm{Cl} 0.79$ to 1.91$)$ & 4 & Low \\
\hline Lionetti et $a l^{12}$ & 6 vs 12 months & HR $0.9(95 \% \mathrm{Cl} 0.6$ to 1.4$)$ & 4 & Low \\
\hline \multirow[t]{3}{*}{ Aronsson et $a^{16}$} & $<17$ weeks & HR $0.59(95 \% \mathrm{Cl} 0.33$ to 1.04$)$ & 3 & Medium \\
\hline & 17-26 (reference) & HR $0.90(95 \% \mathrm{Cl} 0.69$ to 1.18$)$ & & \\
\hline & $>26$ weeks & & & \\
\hline
\end{tabular}

onset. ${ }^{30}$ Indeed, breast milk may independently prevent intestinal infections, which are thought to be one of the triggering factors for $\mathrm{CD}$, modulate the intestinal microbiota, increasing the number of bifidobacteria, and boost the mechanisms of oral tolerance by means of several immunomodulatory molecules, offering a high biological plausibility to the interpretation of a protective effect on immune-mediated diseases such as CD. No studies are, at the moment, available to explain the lack of a protective role of breast feeding on the risk of CD. A recent study, however, revealed that breast milk of mothers with CD has reduced concentrations of immunoprotective compounds (tumour growth factor (TGF) $-\beta 1$ and $\operatorname{sIgA}$ ) and bifidobacteria 16S rRNA gene copy numbers as compared with breast milk of healthy mothers, which could presumably diminish the protective effects of breast feeding on the child's future risk of developing $\mathrm{CD} .^{31}$

A recent prospective study in a cohort of infants at family risk of $\mathrm{CD}$ has shown that the HLA-DQ2/8 genotype may independently contribute to influencing the composition of gut microbiota. ${ }^{72}$ In this regard, the studies investigating the role of breast feeding on CD development have included different control populations with heterogeneous genetic backgrounds, thereby representing a non-controlled variable in most of them. Additional environmental factors that could confound the potential role of breast feeding on $\mathrm{CD}$, directly or via gut microbiota modulation, include mode of delivery, incidence of infections and maternal diet. ${ }^{5} 333^{34}$ These pieces of evidence suggest that a number of host and environmental factors, besides gluten intake, might play a relevant role in the onset of overt $\mathrm{CD}$, thus confounding the statistical analysis on the effect of breast feeding.

\section{Time of gluten introduction and CD}

It is quite clear from our analysis that the age of children at exposure to gluten during the weaning process bears no effect on CD development. Only two papers found a correlation between the time of gluten introduction and development of CD. Norris et $a l^{15}$ found an increased risk for both early and late gluten 
introduction while Strødal $e t a l^{26}$ reported an increased risk for $\mathrm{CD}$ when gluten is introduced after 6 months of age. It is noteworthy that these indices of risk are very mild, with a large variation and a possible role of further residual confounders, therefore showing only a low statistical significance. Both the two recent large, prospective studies demonstrated, with a very solid intervention design, high GRADE score and low bias risk, that neither early (4 months of age) nor late (1 year of age) introduction of gluten impacts the later development of $\mathrm{CD}$, respectively. ${ }^{12}{ }^{13}$ It is noteworthy that, in the Italian multicentre study, the group of baby girls (but not boys) at high genetic risk of $\mathrm{CD}$, carrying the DQ2 haplotypes in homozygosis, who were introduced to gluten earlier (at 6 months) ${ }^{12}$ had a higher prevalence of CD even at 5 years of age. Similarly, in the multicentre European trial, ${ }^{13}$ the girls (and again, not the boys) in the group where gluten was introduced early (at 4 months) had a higher prevalence of CD (21\%) at 5 years of age than those who were first exposed to gluten at 6 months $(8.5 \%)$.

Also considering studies on food allergy, one study (GINIplus and LISAplus) reported that a delayed introduction of solid foods or the avoidance of highly allergenic foods during the first year does not seem to be beneficial for allergy prevention, while only a very early (before week 17 of age) introduction of solids may increase the risk of later manifestations of eczema. ${ }^{35}$ Although CD has an obviously different pathogenetic mechanism with respect to eczema, most epidemiological studies support the hypothesis that, after the fourth month of age, any solid can be safely introduced, without increasing the risk of developing reactions to food antigens. ${ }^{36}$ Accordingly, there is no reason to delay the first exposure to any solid food, including foods considered to be highly allergenic. Theoretically, the immunodevelopmental processes and the generation of regulatory T-cells and cytokines driving oral tolerance are influenced by the structure of the microbiota colonising the newborn intestine, which in turn evolves in time mainly influenced by dietary changes, particularly cessation of breast feeding and the introduction of solids. ${ }^{37}$ Following these considerations, the timing of gluten introduction suggested by the current ESPGHAN commentary on complementary feeding appears outdated and is no longer evidence-supported, since it was drafted before the publication of the studies reviewed here. $^{39}$

The Swedish observations on the celiac epidemic in the late $80 \mathrm{~s}$, which occurred when the amount of gluten given to infants during weaning was dramatically increased, suggest that the amount of gluten itself might have a key role. ${ }^{28}$ However, none of the studies suitable for inclusion into a systematic review have collected information about the load of gluten during the early feeding phases. It is likely that the amount of gluten introduced at weaning might play a pivotal role in triggering $\mathrm{CD}$ in predisposed children. Information about this issue might provide us an important clue to understand how early feeding practices might influence CD development. Studies about the role of varying amounts of gluten given to infants during weaning are not available. Even observations reporting the Swedish epidemic of $\mathrm{CD}$ that occurred after changes in infant feeding practices fail to provide information about the actual amount of gluten that was introduced to the involved infants during weaning.

The generalisability of our results has been enhanced by the involvement of children from both Europe and the USA, and the uniformity of the diagnosis of CD, made by means of the serum positive titre of anti-tTG antibodies and duodenal biopsy.

On the other hand, most of the papers included in our analysis have a high bias risk. Several papers included controls from general populations not selected for at-risk genetic background and others enrolled children at genetic risk for T1DM, a condition partially sharing the same type of genetic predisposition as CD. Within these limits, all the studies that enrolled DQ2 +children, with a prospective design, are in agreement that both breast feeding and the timing of gluten introduction during weaning do not impact on the development of CD.

The results of this systematic review are consistent with those of a recent meta-analysis by Szajewska et $a l{ }^{40}$ which has included the same studies. With respect to that review, we scored the papers according to their bias risk and discussed the results from a different angle, including the data that support a role for additional variables in the development of $\mathrm{CD}$, such as differences in microbiota and breast milk composition. On the contrary, the paper by Szajewska et al is focused exclusively on the role of gluten introduction into the diet.

In conclusion, there is currently no evidence to recommend avoiding either an early (at 4 months of age) or a late (at or after 6 or even 12 months) gluten introduction in children at risk of CD. The possible exception of DQ2 homozygous girls, ${ }^{12}{ }^{13}$ where an early introduction of gluten appears to be associated with a greater risk of subsequent development of CD must, however, be acknowledged, and requires further study, possibly representing an early manifestation of 'medicine of gender'. Accordingly, no specific general recommendations about gluten introduction or optimal breastfeeding duration can be presently provided on evidence-based criteria.

Even in the absence of evidence of the protective effect of breast feeding, it must be reiterated that breast feeding should be implemented whenever possible in all infants, including those at genetic risk for CD, for its many, well-documented benefits, including its unique role in maternal-infant bonding.

Further studies that include variables so far neglected are needed to progress in the identification of critical factors and predictive models of CD development. 
Contributors MS conceptualised and designed the study, performed the PubMed, EMBASE and Web of Science search, selected the papers to be included in the review, extracted and analysed the data, drafted the initial manuscript and approved the final manuscript as submitted. CA designed the study, performed the PubMed, EMBASE and Web of Science search, selected the papers to be included in the review, extracted the data, drafted the initial manuscript and approved the final manuscript as submitted. YS selected the papers to be included in the review, extracted and analysed the data, drafted the initial manuscript and approved the final manuscript as submitted. SG analysed the data, critically reviewed the manuscript and approved the final manuscript as submitted. All the authors approved the final manuscript as submitted and agree to be accountable for all aspects of the work.

Funding Intramural.

Competing interests None declared.

Provenance and peer review Not commissioned; externally peer reviewed.

Data sharing statement Additional data can be accessed via the Dryad data repository at http://datadryad.org/ with the doi:10.5061/dryad.72t83.

Open Access This is an Open Access article distributed in accordance with the Creative Commons Attribution Non Commercial (CC BY-NC 4.0) license, which permits others to distribute, remix, adapt, build upon this work noncommercially, and license their derivative works on different terms, provided the original work is properly cited and the use is non-commercial. See: http:// creativecommons.org/licenses/by-nc/4.0/

\section{REFERENCES}

1. Sollid LM, Jabri B. Triggers and drivers of autoimmunity: lessons from coeliac disease. Nat Rev Immunol 2013;13:294-302.

2. Meresse B, Malamut G, Cerf-Bensussan N. Celiac disease: an immunological jigsaw. Immunity 2012;36:907-19.

3. Jabri B, Kasarda DD, Green PH. Innate and adaptive immunity: the yin and yang of celiac disease. Immunol Rev 2005;206:219-31.

4. Lionetti E, Catassi C. New clues in celiac disease epidemiology, pathogenesis, clinical manifestations, and treatment. Int Rev Immunol 2011;30:219-31.

5. Stene LC, Honeyman MC, Hoffenberg EJ, et al. Rotavirus infection frequency and risk of celiac disease autoimmunity in early childhood: a longitudinal study. Am J Gastroenterol 2006;101:2333-40.

6. Emilsson L, Magnus MC, Størdal K. Perinatal risk factors for development of celiac disease in children, based on the prospective Norwegian Mother and Child Cohort Study. Clin Gastroenterol Hepatol 2015;13:921-7.

7. Olivares M, Neef A, Castillejo G, et al. The HLA-DQ2 genotype selects for early intestinal microbiota composition in infants at high risk of developing coeliac disease. Gut 2015;64:406-17.

8. Silano M, Agostoni C, Guandalini S. Effect of the timing of gluten introduction on the development of celiac disease. World $J$ Gastroenterol 2010;16:1939-42.

9. Guyatt $\mathrm{GH}$, Oxman AD, Vist GE, et al. GRADE: an emerging consensus on rating quality of evidence and strength of recommendations. BMJ 2008;336:924.

10. Wells GA, Shea B, O'Connell D, et al. The Newcastle-Ottawa Scale (NOS) for assessing the quality of non randomised studies in meta-analyses. 2011. http://www.ohri.ca/programs/clinical epidemiology/oxford.asp (accessed April 2015).

11. Higgins JP, Altman DG, Gøtzsche PC, et al. The Cochrane Collaboration's tool for assessing risk of bias in randomised trials. BMJ 2011;343:d5928.

12. Lionetti $\mathrm{E}$, Castellaneta $\mathrm{S}$, Francavilla $\mathrm{R}$, et al. Introduction of gluten HLA status, and the risk of celiac disease in children. $N$ Engl $J$ Med 2014;371:1295-303.

13. Vriezinga SL, Auricchio R, Bravi E, et al. Randomized feeding intervention in infants at high risk for celiac disease. $N$ Engl $J$ Med 2014;371:1304-15

14. Ziegler AG, Schmid $S$, Huber $D$, et al. Early infant feeding and risk of developing type 1 diabetes-associated autoantibodies. JAMA 2003;290:1721-8.
15. Norris JM, Barriga K, Hoffenberg EJ, et al. Risk of celiac disease autoimmunity and timing of gluten introduction in the diet of infants at increased risk of disease. JAMA 2005;293:2343-51.

16. Aronsson CA, Hye-Seung $\mathrm{L}$, Liu $\mathrm{E}$, et al. Age at gluten introduction and risk of celaic disease. Pediatrics 2015;135:239-45.

17. Auricchio $S$, Follo $D$, de Ritis $G$, et al. Does breast feeding protect against the development of clinical symptoms of celiac disease in children? J Pediatr Gastroenterol Nutr 1983;2:428-33.

18. Greco L, Auricchio S, Mayer M, et al. Case control study on nutritional risk factors in celiac disease. J Pediatr Gastroenterol Nutr 1988;7:395-9.

19. Fälth-Magnusson K, Franzén L, Jansson G, et al. Infant feeding history shows distinct differences between Swedish celiac and reference children. Pediatr Allergy Immunol 1996;7:1-5.

20. Ascher H, Krantz I, Rydberg L, et al. Influence of infant feeding and gluten intake on coeliac disease. Arch Dis Child 1997;76:113-17.

21. Ivarsson $\mathrm{A}$, Hernell $\mathrm{O}$, Stenlund $\mathrm{H}$, et al. Breast-feeding protects against celiac disease. Am J Clin Nutr 2002;75:914-21.

22. Welander A, Tjernberg AR, Montgomery SM, et al. Infectious disease and risk of later celiac disease in childhood. Pediatrics 2010;125:e530-6.

23. Peters U, Schneeweiss S, Trautwein EA, et al. A case-control study of the effect of infant feeding on celiac disease. Ann Nutr Metab 2001;45:135-42.

24. Decker E, Engelmann G, Findeisen A, et al. Cesarean delivery is associated with celiac disease but not inflammatory bowel disease in children. Pediatrics 2010;125:e1433-40.

25. Roberts SE, Williams JG, Meddings D, et al. Perinatal risk factors and coeliac disease in children and young adults: a record linkage study. Aliment Pharmacol Ther 2009;29:222-31.

26. Størdal K, White RA, Eggesbø M. Early feeding and risk of celiac disease in a prospective birth cohort. Pediatrics 2013;132:e1202-9.

27. Jansen MA, Tromp II, Kiefte-de Jong JC, et al. Infant feeding and anti-tissue transglutaminase antibody concentrations in the Generation R Study. Am J Clin Nutr 2014;100:1095-101.

28. Ivarsson A, Myléus A, Norström F, et al. Prevalence of childhood celiac disease and changes in infant feeding. Pediatrics 2013;131: e687-94.

29. Akobeng AK, Ramanan AV, Buchan I, et al. Effect of breast feeding on risk of coeliac disease: a systematic review and meta-analysis of observational studies. Arch Dis Child 2006;91:39-43.

30. Szajewska H, Chmielewska A, Pieścik-Lech M, et al. Systematic review: early infant feeding and the prevention of coeliac disease. Aliment Pharmacol Ther 2012;36:607-18.

31. Olivares M, Albrecht S, De Palma G. Human milk composition differs in healthy mothers and mothers with celiac disease. Eur $J$ Nutr 2015;54:119-28.

32. Palma GD, Capilla A, Nova E, et al. Influence of milk-feeding type and genetic risk of developing coeliac disease on intestinal microbiota of infants: the PROFICEL study. PLOS ONE 2012;7: e30791.

33. Mårild K, Stephansson $\mathrm{O}$, Montgomery $\mathrm{S}$, et al. Pregnancy outcome and risk of celiac disease in offspring: a nationwide case-control study. Gastroenterology 2012;142:39-45.

34. Størdal K, Haugen M, Brantsæter AL, et al. Association between maternal iron supplementation during pregnancy and risk of celiac disease in children. Clin Gastroenterol Hepatol 2014;12:624-31.e1-2.

35. Sausenthaler S, Heinrich J, Koletzko S, GINIplus and LISAplus Study Groups. Early diet and the risk of allergy: what can we learn from the prospective birth cohort studies GINIplus and LISAplus? Am J Clin Nutr 2011;94(6 Suppl):2012S-7S.

36. Nwaru BI, Erkkola M, Ahonen S, et al. Age at the introduction of solid foods during the first year and allergic sensitization at age 5 years. Pediatrics 2010;125:50-9.

37. Verhasselt V. Oral tolerance in neonates: from basics to potentia prevention of allergic disease. Mucosal Immunol 2010;3:326-33.

38. Bergström A, Skov TH, Bahl Ml, et al. Establishment of intestinal microbiota during early life: a longitudinal, explorative study of a large cohort of Danish infants. Appl Environ Microbiol 2014;80:2889-900.

39. Agostoni C, Decsi T, Fewtrell M, et al. Complementary feeding: a commentary by the ESPGHAN Committee on Nutrition. J Pediatr Gastroenterol Nutr 2008;46:99-110.

40. Szajewska H, Shamir R, Chmielewska A, et al. Systematic review with meta-analysis: early infant feeding and coeliac disease-update 2015. Aliment Pharmacol Ther 2015;41:1038-54. 